\title{
New Structural Economics: A Framework for Rethinking Development and Policy
}

\section{Justin Yifu Lin}

Washington, DC: World Bank, 2012, pp. 371

ISBN 978-0-8213-8955-3

doi:10.15179/ces.16.1.6

The book entitled New Structural Economics: A Framework for Rethinking Development and Policy is a result of the author's research on New Structural Economics (NSE) conducted in the period from 2008 to 2011 while he was the Chief Economist and Senior Vice President of the World Bank, as the first person from a developing country to hold that position. Within his research program, Lin analyzed (individually and in co-authorship) the process of industrialization and the causes of lagging growth in developing countries. As such, the book represents a significant contribution to the research on economic development, with special focus on determinants of economic growth in low-income countries which has been at the centre of economic research for a long period of time now.

Besides the introduction, the book is comprised of the following seven chapters: (1) "New Structural Economics: A Framework for Rethinking Development";

(2) "The Growth Report and New Structural Economics" (co-authorship with Célestin Monga); (3) "Growth Identification and Facilitation: The Role of the State in the Dynamics of Structural Change" (co-authorship with Célestin 
Monga); (4) "Applying the Growth Identification and Facilitation Framework: The Case of Nigeria" (co-authorship with Volker Treichel); (5) "Financial Structure and Economic Development" (co-authorship with Lixin Colin Xu); (6) "Development Strategy, Institutions and Economic Performance" and (7) "Epilogue: The Path to a Golden Age of Industrialization in the Developing World".

In the introduction, and especially in the first chapter entitled "New Structural Economics: A Framework for Rethinking Development", the author describes the evolution of economic thinking in this research area and provides arguments in favor of the NSE. He points out that the recent global economic crisis puts pressure on the "revision" of previous economic theories developed since Adam Smith. Moreover, growth performance of developing countries such as China, Brazil, Singapore and India, which did not follow policy recommendations of dominant development theories, intensified discussions on the issues of main factors behind achieving economic growth. Therefore, as a first step towards an insight into the nature and determinants of economic growth, the author describes previous theories of development and brings NSE to the centre of this debate.

Specifically, Lin divides the evolution of development theories into three phases which he describes as "waves": (1) structuralist economics that emerged in Latin America during the 1940s; (2) a set of neoliberal policies based on neoclassical economics, also known as Washington consensus during the 1990s and (3) New Structural Economics. In the first phase of development research, a gap between countries was explained by structural differences as a result of market failures. Furthermore, relying on Keynesianism, economists have advocated government intervention and structural reforms as instruments for dealing with market imperfections and reducing the gap in development of industrialized and developing countries. However, the failure of this approach (especially in Latin American countries) prompted the next wave of research which emphasized the essential function of markets in allocating resources and providing development incentives. This approach, on the other side, ignored structural differences 
between countries and expected structural change to happen spontaneously in the development process. Despite the fact that the approach of Washington Consensus which promoted liberalization, privatization and stabilization, was advocated by many international development organizations, it resulted in various controversies in terms of growth and employment. As mentioned, the countries that have achieved remarkable growth during the 20th century did not follow its basic tenets. Therefore, the author highlights that it became obvious that insufficient attention was given to the heterogeneity and specific characteristics among individual countries. As a result, a third wave of research emerged. This line of development theories holds that, although markets should be a fundamental mechanism in allocating resources, governments should also play a more significant role in coordinating investments and in compensating for externalities generated by the first movers in the growth process.

Thus, Lin defines NSE as an attempt to set out this third wave of research, postulating that the economic structure is endogenous to the factor endowment structure: sustained economic development is driven by changes in factor endowments that determine the country's comparative advantages and thus its optimal industrial structure. On the other side, the best way to upgrade a country's endowment structure is to develop industries according to these comparative advantages. Specifically, the author summarizes three basic ideas which are at the centre of NSE. First, since the economy's structure of factor endowments evolves depending on the level of development, the industrial structure of economy will also vary with different development levels. Second, each level of development is a point on the continuum from low-income to high-income economy (rather than a dichotomy of two development levels). Finally, at each level of development, the market is the underlying mechanism for effective resource allocation, while the government plays an active role in facilitating structural changes.

The first chapter includes comments by Anne Krueger, Dani Rodrik and Joseph Stiglitz. While Anne Krueger raises the question regarding the ability of governments to identify the winners, i.e. industries with latent comparative advantage and industry-specific provision of infrastructure (p. 51); Joseph 
Stiglitz argues that the government (besides its restrictive role) must also play a constructive and catalytic role in promoting entrepreneurship, human capital development, technology and innovation (p. 57). In addition, Krueger points at the possibility of New Structural Economics becoming just a licence for governments to support specific industries and firms. Finally, Rodrik points out that Lin actually wants to merge structuralism with the neoclassical economic theories and he welcomes this idea. However, regarding Lin's recommendation that today's industrial policy should be aware of the government failure and focus specifically on market failures rather than on vague shortcomings of the private sector, Rodrik implies that in practice this is rather complicated to achieve since market distortions cannot always be identified, and targeted remedies may not always be available (p. 55).

The second chapter, "The Growth Report and New Structural Economics", describes how NSE builds on previous theories and compares its basic predictions with stylized facts of successful countries identified by "The Growth Report: Strategies for Sustained Growth and Inclusive Development" (Commission on Growth and Development, 2008). This report identified five stylized facts or characteristics of high-growth countries. These are the openness to the global economy, macroeconomic stability, high saving and investment rates, market allocation and governance. In addition, Lin and Monga focus on structural and technological change as key elements of the growth strategy, thereby explaining the endogeneity and exogeneity issues surrounding the stylized facts. Authors also discuss the principle of comparative advantage and the role of government in facilitating structural transformation as key aspects of NSE. They argue that developing countries that adopt economic policies contradictory to the comparative advantages (i.e. comparative-advantage-defying, CAD) are faced with greater macroeconomic instability, large budget deficits, financial repression etc. On the other hand, countries that implement comparative-advantagefollowing (CAF) strategies are more likely to achieve dynamic economic growth. These theoretical predictions are also empirically tested by Lin in Chapter 6 . 
In the third chapter entitled "Growth Identification and Facilitation: The Role of the State in the Dynamics of Structural Change", Lin and Monga further describe "Growth Identification and Facilitation Framework" (GIFF) as an approach for policy-makers to facilitate the implementation of structural changes based on the assumptions of NSE. They describe a six-step approach that policy-makers could use in the process of identifying industries that are consistent with country's latent comparative advantages. First step is to identify new industries with potential comparative advantages in order to identify goods and services that were growth drivers in countries with similar endowment structures. Second, if such companies already exist in these sectors, it is necessary to remove barriers that impede them from becoming the country's comparative advantage. Furthermore, if there are no domestic enterprises in such sectors, policy-makers need to attract FDI from similar higher-income countries. The fourth step is related to the provision of support to scale up identified industries. Fifth, in developing countries with poor infrastructure and unfriendly business environment, the government can invest in various economic zones and industrial parks which can reduce transaction costs and facilitate industrial development. In the sixth step, the government may provide incentives to domestic enterprises or foreign investors which would reduce the time and financial costs that companies face. Authors argue that by implementing the described approach, governments could play an active role in the facilitation of structural transformation and industrial upgrading. Finally, authors explain why industrial policy often does not result in expected outcomes, and provide arguments against the government's policy of protecting selected companies and industries that actually distort the comparative advantage of countries.

This chapter also includes comments by Dirk Willem te Velde, Suresh Tendulkar, Alice Amsen, K.Y. Amoako, Howard Pack and Wonhyuk Lim. Most of them agree that the approach offered by Lin and Monga provides important implications for industrial development and that it is very close to becoming the new growth "recipe". However, they also raise doubts about the ability of countries to implement these recommendations, especially regarding the role of 
the state in identifying the specific industries as drivers of growth, as Tendulkar emphasized (p. 188). Several issues come at the centre of debate from this aspect. First, even if countries would identify the right industries and constraints that need to be removed, it is still possible that wrong policy instruments might lead to unintended outcomes (te Velde, p. 182). Moreover, selecting industries based on the experience of developed benchmark countries is difficult to implement since governments should address a wider list of issues, much more complex than simply looking at products and services that were drivers of growth in richer countries, as emphasized by Pack (p. 199). Finally, some comments also suggest that countries that want to accelerate their industrial catch-up should actually defy its current comparative advantage to some extent, involving a whole set of policies that need to be implemented in order to increase the chances of industrial policy success (Amaoko, p. 195).

The fourth chapter, "Applying the Growth Identification and Facilitation Framework: The Case of Nigeria", illustrates how to apply GIFF (growth identification and facilitation framework) in developing countries, using the example of Nigeria. Authors (Lin and Trechel) identify benchmark countries and choose a number of industries in which Nigeria has potential comparative advantage relative to selected countries. They conclude that targeted interventions to promote growth should focus on the provision of physical infrastructure, improving the business environment, developing the education system, trade reform, the provision of tax incentives, access to finance and access to foreign exchange. The authors also discuss binding constraints to growth in each of the identified industry's value chains as well as potential mechanisms through which governance issues in the implementation of industrial policy could be addressed. These mechanisms encompass transparency and accountability, proper definition of expected outcomes, limiting the degree of government intervention and delegating the identification and selection of industries to external experts.

In the fifth chapter, "Financial Structure and Economic Development", Lin and $\mathrm{Xu}$ focus on the issues of financial structure and financial depth. They analyze both empirical and theoretical views regarding the effects of financial structure 
on economic development, as well as the role that banks and stock markets play in countries at different development stages. Specifically, as they point out, financial structure varies among countries as well as within countries, depending on the different levels of development. Therefore, the authors argue that the optimal financial structure of the economy is endogenous to real demand for financial services based on industrial structure, which then hinges on country's comparative advantages. Moreover, contrary to previous findings, the authors imply that financial structure (and not the depth of financial markets) is crucial for economic development. In this line of thinking, they stress that bank development (relative to stock market development) has particularly strong and significant effects on economic development in poor and institutionally weak countries. Finally, authors describe the circumstances under which the actual structure of financial markets deviates from its optimal structure that changes with each development stage. According to Lin and $\mathrm{Xu}$, this deviation can be a result of politics, legal origins or government preferences and beliefs. In turn, deviation of a country from its optimal financial structure is related to a loss in efficiency and lower income level.

Sixth chapter, "Development Strategy, Institutions and Economic Performance”, provides an overview of the results of previous empirical studies which supported the assumption that countries following the development strategy based on comparative advantages (CAF) achieved better results (in terms of higher growth rates, lower economic volatility and lower inequality) than countries that have implemented strategies that are contradictory to CAF (i.e. CAD). Based on these findings, the author believes that the growth failure of countries results from inappropriate development strategies implemented by policy-makers. Lin's main message is that, while in the past governments placed great attention on the development of certain capital-intensive industries, it is essential to focus their efforts towards upgrading the country's endowment structure and creating a favorable environment for the development sectors aligned with its comparative advantages. Therefore, in the second part of this chapter he empirically tested the effects of both the CAF and CAD strategies on economic performance, on a 
sample of 122 countries in the period from 1962 to 1999 . As a proxy variable for $\mathrm{CAD}$, the author uses the relative size of capital-intensive production while also including a variety of institutional control variables (index of economic freedom, the costs of starting a business, ratio of trade dependence etc.). The obtained results indicate that the CAD strategy indeed has a statistically significant negative effect on growth and leads to an increase in inequality. The author argues that the government that adopts a CAD strategy which attempts to encourage firms to ignore the existing comparative advantages of the economy in their entry (choice) of industry (technology) is responsible for giving firms subsidies in order to compensate for losses arising from policy burdens and cannot distinguish these losses from operational ones. The firms will then lobby government for both ex ante and ex post policy favors. In this case, the economy will be full of rent-seeking and unproductive profit-seeking activities which hinder economic growth.

In the final chapter, "Epilogue: The Path to a Golden Age of Industrialization in the Developing World", based on the findings from previous chapters, Lin concludes that low-income countries should turn their status of latecomers to their advantage and implement the six-step procedure described in the third chapter. Lin highlights that his belief is based on the potential of developing countries to expand their industrial structures. So, what the author offers in this book is one of the possible ways of achieving rapid industrialization in low-income countries. Accordingly, Lin points out that the golden age of industrialization in developing countries is just beginning.

Although this book represents a significant contribution to the research on developing countries' ability of generating sustainable economic growth, ideas presented by the author do not differ much from existing theories and models. Moreover, as Rodrik implies in the first chapter (p. 53) of this book, Lin takes the best from neoclassical and structuralist approaches, which is why New Structural Economics can be viewed as an alternative to already existing recommendations and recipes for achieving higher growth rates. For example, as stated by one of the commentators in the book (te Velde, p. 181), the approach followed by Lin 
complements the growth diagnostics approach developed by Hausmann, Rodrik and Velasco (2005), competitiveness analysis approach developed by Porter and Schwab (2008) and investment climate analysis approach (World Bank, 2004). However, the process of designing and implementing specific policies aimed at increasing growth rates is characterized by a high degree of complexity which can result in unexpected or unsustainable final outcomes. Therefore, since the author assigns a proactive role to government, future research should pay more attention to the specific (political and economic) factors that may have a significant impact on the government incentives in the implementation of certain policies. These aspects could be of great importance for the fulfilment of each of the six steps outlined in the fourth chapter. Therefore, the question on the countries' ability to use prescribed "recipes" is reasonable. As it has been shown, the reforms that have been implemented in many developing countries during the 1990s did not result in the expected outcomes and it became clear that there is no universal model for implementation of policies aimed at achieving overall economic progress, without taking into consideration heterogeneity between countries. Different countries require different approaches, and the efficiency of some of the generally accepted recommendations (such as the recommendations encompassed by the Washington Consensus) depends on specific circumstances in individual countries. Having this in mind, Lin offers potential ways to achieve rapid industrialization as growth factor in a specific group of low-income countries.

In this book readers can find a comprehensive overview of the evolution of development theories with the novelty of introducing the New Structural Economics into the third wave of this line of research, emphasizing the important roles of both market and government in promoting economic development. We can conclude that, although the book New Structural Economics. A Framework for Rethinking Development and Policy represents an important contribution to the debate on the issue of the dynamic economic growth, taking into account problems of exogeneity and endogeneity associated with the existing growth strategies, it does not offer a finite answer on drivers of growth in lowincome countries. The research is constantly faced with many challenges and 
controversies in finding an optimal "policy mix" for achieving sustainable economic growth and development. As Bergsten and Williamson (1994: 4) once stressed, although there is no set of rules that could provide a kind of manual for all countries in all circumstances, any guidelines that result from detailed examination of specific processes in individual countries could be helpful to policy-makers and economists. Therefore, this book is highly recommended to academics, government officials, consultants and all those studying economics as an intriguing additional reading.

\section{Literature}

Bergsten, C. Fred and John Williamson, 1994, "Introduction" in John Williamson, ed., Political Economy of Policy Reform, pp. 1-8, Washington, DC: Institute for International Economics.

Commission on Growth and Development, 2008, The Growth Report. Strategies for Sustained Growth and Inclusive Development, Washington, DC: World Bank.

Hausmann, Ricardo, Dani Rodrik and Andrés Velasco, 2005, "Growth Diagnostics" in Joseph E. Stiglitz and Narcís Serra, eds., The Washington Consensus Reconsidered: Towards a New Global Governance, pp. 324-355, Oxford: Oxford University Press.

Porter, Michael and Klaus Schwab, 2008, The Global Competitiveness Report 2008-2009, Geneva: World Economic Forum.

World Bank, 2004, World Development Report 2005. A Better Investment Climate for Everyone, New York, NY: Oxford University Press.

Valentina Vučković The Institute for Development and International Relations 